\title{
Escalabilidade nos filmes de Alexander Kluge: estratégia para evitar a catástrofe
}

\author{
Jane de Almeida \\ https://orcid.org/0000-0003-1520-0729 \\ I - Universidade Mackenzie. \\ São Paulo (SP), Brasil
}

Resumo: O artigo reflete sobre o conceito de escalabilidade na obra do cineasta alemão Alexander Kluge, pensando nos efeitos provocados pelo deslocamento do filme analógico para o filme computadorizado. Por meio de citações em filmes e entrevistas, o artigo aponta momentos e formas de escalabilidade na obra de Kluge, analisando as escalabilidades temporais e espaciais que também se deslocam para uma escalabilidade a partir de dados digitais. Ao final, o artigo apresenta parte de entrevista inédita feita com o cineasta sobre a internet e os novos meios digitais de comunicação e representação.

Palavras-Chave: escalabilidade, Alexander Kluge; filme computadorizado.

Abstract: Scalability in the films of Alexander Kluge: strategy to avoid catastrophe - The paper reflects on the concept of scalability in the work of the German filmmaker Alexander Kluge, pondering on the effects caused by the shift from analog film to computerized film. Through citations and interviews of his films, the article points out moments and forms of scalability in Kluge's work reflecting on the temporal and spatial scalabilities that also move to digital data. Ultimately, the article presents part of an unpublished interview with the filmmaker on the Internet and the new digital media of communication and representation.

Keywords: scalability; Alexander Kluge; digital film.

\section{O elefante bêbado}

As entrevistas realizadas pelo cineasta alemão Alexander Kluge geralmente envolvem apenas duas pessoas, ele e seu entrevistado, em língua alemã. No entanto, na entrevista 
chamada O amor cego: conversa com Jean-Luc Godard (Blinde liebe: gespräch mit Jean-Luc Godard, (2001), Kluge adota o método de Godard em O Desprezo (1963): e mantém a tradutora em cena, mediando a língua francesa e a alemã. Essa entrevista tem a particularidade de colocar juntos dois icônicos cineastas europeus, realizadores de um cinema preocupado com o pensamento, além do fato de Kluge afirmar que Godard é uma de suas fontes de inspiração. Durante a entrevista, Kluge tem a oportunidade de dizer a Godard diretamente que o considera um "guia imaginário do cinema, de uma segunda via, pois a primeira está destruída". A entrevista coloca em quadro Godard e a tradutora Ulrike Sprenger e Kluge comparece com sua mão e sua voz, que é um elemento notável em seus filmes e entrevistas. ${ }^{1}$ Composta por intertítulos, imagens dos filmes de Godard e desenhos de livros sobre os quais a entrevista versa, trata-se de um encontro entre dois gigantes, principalmente para os cinéfilos. As perguntas que são dirigidas a Godard são respondidas gentilmente, em um fluxo de respostas aparentemente despreocupado com relação à forma ou ao conteúdo da conversa, porém com certo distanciamento.

Após algumas perguntas sobre Elogio do amor (2001), filme que Godard estava lançando, Kluge pergunta-lhe sobre como seria realizar um filme às cegas, tema tratado em seu filme anterior $O$ ataque do presente contra o resto do tempo (1985), chamado em inglês de Blind Director. Godard devolve a questão para Kluge que não a responde diretamente, passando para outras perguntas. Na época em que seu o filme fora lançado, Kluge respondeu a uma entrevista dizendo o seguinte: "É verdade. Eu não faço filmes com meus olhos. Eu poderia ter um amigo para me dizer como as imagens são" (INDIANA, 1989).

Mais adiante, Kluge continua conduzindo a entrevista com perguntas sobre os órgãos de sentido: "são os ouvidos mais antigos que os olhos? E a pele, nosso maior órgão?". Por meio dessa associação, Kluge traz para a entrevista seu bicho de estimação: o elefante, objeto de estranhamento e familiaridade de outros filmes como Artistas na cúpula do circo: perplexos (1967), A indomável Leni Peickert (1967-69), A execução de um elefante (2007), além da inesquecível elefanta acrobata Jenny em A patriota (1979). Kluge, ao lembrar que a pele humana é o nosso maior órgão, diz também que ela é nosso atributo de "elefante" e obtém de Godard a encantadora associação entre a sensibilidade do "negativo" fílmico e os problemas de pele que desenvolve ao iniciar uma filmagem. Interessante observar que a classe dos elefantes pertence à categoria dos paquidermes, que significa "de pele grossa" (do grego pakchydermos).

Há uma antiga parábola associada ao elefante como metáfora da realidade chamada "o elefante e os homens". De origem indiana, a história foi espalhada pelo mundo ocidental no século XIX, em forma de poema e usada tanto pelo senso comum como pela filosofia, para evidenciar as discordâncias a respeito de um fenômeno, além da dificuldade de se compreender a integralidade dele. A versão sufi muçulmana da parábola relata a história de um "elefante no escuro" que é tocado cegamente, levando a diversas descrições

1 Ver Hansen (1988, p. 178-198) e Farocki em entrevista para Elsaesser (2004, p. 188). 
do imenso animal, pois cada parte será referida como um objeto particular e diferente dos outros. O conto chega à conclusão de que "o olho sensual é como a palma da mão que não é capaz de compreender o animal como um todo" (ARBERRY, 2006, p. 71).

Os elefantes de Kluge são, a princípio, elementos de estranhamento com a função de deslocar o espectador para o campo da metáfora. Também têm sido pensados como elementos de construção de espaço e memória, característica reconhecida do animal. John E. Davidson, para articular seus argumentos sobre os elefantes na obra de Kluge relacionados ao espaço e à memória, lembra que a maior parte das leituras teóricas conectam sua obra à questão do tempo. Examinando dois elementos tão díspares como espaço e elefante, o autor pretende mostrar "que para Kluge um novo sentido de tempo não pode ser experimentado sem construções espaciais que cegam momentaneamente e ainda evocam a liberdade" (DAVIDSON, 2011, p. 21).

Recentemente, com a eleição de Donald Trump, Kluge usou a imagem do elefante bêbado para pensar o fenômeno de sua vitória nos Estados Unidos (OBRIST, 2017). Na biografia de Max Weber, há uma conhecida polêmica sobre sua tendência à embriaguez, além de sugestões a respeito de seus sweet dreams sobre "ter a tromba de um elefante". O historiador e biógrafo Joachim Radkau argumenta que Weber confirmava a crença de que os elefantes são inclinados ao álcool, como um fenômeno natural e não cultural (sabe-se hoje que este fato não é verdadeiro), assim como a crença de que o heroísmo é também um fenômeno natural, sugerindo uma associação que intitula seu artigo: "O heróico êxtase dos elefantes embriagados" (RADKAU, 2006, p. 533). No artigo, Radkau também lembra que "carisma" foi a mais bem-sucedida invenção conceitual de Max Weber, ao deslocar seu sentido do campo religioso para o político. Kluge concatena essas cadeias mostrando o processo identificatório do indivíduo torturado pela realidade, com o gozo do indisciplinado que rompe as fronteiras do não-permitido ostensivamente. Kluge faz o seguinte comentário: "Essa falta do controle individual, juntamente com mentira e propaganda, pertence ao carisma do ditador. A falta de controle dos controladores. O gordo Göring que roubou tantas pinturas na Europa". Kluge então acrescenta: "Max Weber viu isso!" (OBRIST, 2017).

O curador de arte contemporânea Hans Ulrich Obrist, continuando sua entrevista com o cineasta, faz a seguinte pergunta: "Então, você sempre amou elefantes?". Kluge responde: "Sim, sempre amei elefantes. Meus avós eram simples camponeses. Quando criança, vi dois elefantes no circo. O que eu faço não é arte. É gravar alguma coisa através da ótica da arte como uma lente" (OBRIST, 2017).

\section{Escalabilidade}

Mais adiante na entrevista com Godard, Kluge lança a imagem do gigante Micrômegas deVoltaire, elemento que relaciona as questões a respeito dos órgãos de sentido que haviam 
sido anteriormente abordadas e agora, não apenas com o ponto de vista do "elefante", mas com um processo de escalabilidade da perspectiva do espaço exterior. Micrômegas, um anão da "galáxia" de Sirius, vem à terra e encontra microsseres, que são os humanos. O gigante tem 20.000 pés de altura (por volta de 39 quilômetros) e uma capacidade perceptiva de 1000 sentidos para conhecer o mundo, enquanto os pequenos humanos só têm cinco. Na entrevista, a partir da cartela de intertítulo "Besuch Eines Reisenden Vom Sirius" (Visita de um viajante de Sirius), Kluge inicia o assunto relatando que "era fascinado pelo habitante de Sirius de Voltaire". Pergunta então a Godard "se um visitante de Sirius, como Voltaire o descreve, viesse para a humanidade, como você lhe explicaria o que é o cinema, o filme? Você falaria sobre o cinema, o filme ou o conteúdo do filme?" Godard fica algum tempo estático, com olhar pensativo e Kluge insiste: "o que você diria? Não é um livro." Godard então responde:

\begin{abstract}
eu lhe diria que há um instrumento particular que é a câmera, que é uma metáfora, alguma coisa da antiguidade, que é um dispositivo que às vezes é necessário para ver a humanidade assim como um telescópio para ver à distância ou um microscópio para ver de perto, ou óculos para ver melhor. Um instrumento que surge no início do século XX e que certos artistas detém o poder de serem seus chevaliers servants (GODARD, 2001).
\end{abstract}

Interessante observar que Micrômegas foi um artifício usado por Voltaire para abordar a ignorância humana a respeito da realidade, assim como sua arrogância sobre o que a humanidade acredita conhecer, escalando essa realidade do micro ao macro e do macro ao micro. Voltaire toma como referência um espaço exterior cuja perspectiva ultrapassa o sistema solar e historicamente remonta à antiguidade egípcia e à grega que deu o nome de "estrela do cão" a Sirius que, por sua vez, significa "brilho" e era a estrela anunciadora do calor do verão (EVANS, 1998, p. 5), construindo um arco do passado com o espaço exterior. Voltaire escreve seu conto estabelecendo uma escala cósmica para o pensamento filosófico iluminista, elevando a medida espacial de sua época, assim como os astrônomos antigos que estabeleceram medidas do planeta Terra por meio da estrela Sirius. O conto é tomado por medidas de tamanho e proporções, algumas muito corretas, mas com referência marcadamente humana: os pés.

Um outro aspecto interessante do conto de Voltaire é que Micrômegas e o anão de Saturno, seu companheiro de viagem, avistam em 1752 (ano em que o "conto filosófico" foi escrito) as duas luas de Marte, oficialmente descobertas por Asaph Hall só em 1877, no entanto previstas logicamente por Johannes Kepler.

A palavra "escalabilidade" tem particularidades que a colocam em suspenso nas humanidades. Ela sequer existe como substantivo nos dicionários da língua portuguesa ou da língua francesa, apesar de ser encontrada em dicionários das línguas alemã e inglesa (DE ALMEIDA, 2014). Nos últimos tempos, seu uso tem se tornado frequente 
nos campos da computação e economia, com algum uso em sociologia aplicada e tem aparecido com certa regularidade em textos acadêmicos da língua portuguesa. Escalabilidade é a "capacidade de algo", especialmente um sistema de computador, de "se adaptar ao aumento da demanda", dizem os cientistas da computação e os economistas para simplificar o entendimento do conceito. Em economia, mais precisamente, o termo é usado para se referir à capacidade de expansão de um modelo de negócio para alcançar maior eficiência e rentabilidade. A palavra se calcifica com o evento do computador para tentar dar conta do crescimento exponencial da população, dos dados, das galáxias, dos micróbios, dos genes, do meio-ambiente, das contas bancárias. No entanto, tradicionalmente, escalabilidade é importante parte da perícia dos cartógrafos. Cogita-se que Ptolomeu tenha feito os primeiros mapas com escala no seu Geographia (por volta do ano 150) e sabe-se que os chineses foram cartógrafos com excelente capacidade de escalabilidade de mapas, pelo menos a partir do século III.

As razões para scaling podem variar dependendo das áreas que a envolvem e podem implicar em correlacionar valores de diferentes ordens, em um exercício constante de transformação de unidades conhecidas em outras unidades. Mas a maior parte do raciocínio de escala tem a ver com as unidades de "grão" e "extensão", com o olho humano no meio como parâmetro. No caso da entrevista, Kluge quer fazer Godard falar sobre o que é o cinema e certamente já o ouviu falar sobre o assunto diversas vezes, além de ter visto inúmeros de seus filmes como Histoires du Cinéma (1998), Pierrot le fou (1965) e Le Mépris (1963), nos quais expressa diretamente suas ideias sobre o assunto. Mas agora não apenas do ponto de vista da história, mas de outro, cuja escala dimensiona também o tempo e o espaço. As respostas de Godard relacionam o dispositivo do cinema com outros instrumentos visuais e não deixa de fora a associação com o conceito de inconsciente óptico de Walter Benjamin.

Na obra de Kluge, uma lembrança imediata sobre associação por escala é o tema da guerra como sua visão abstrata da morte à distância. No filme O poder dos sentimentos (1986), as imagens intermediadas por uma visão binocular, intercaladas pela monocular, iniciam e entrecortam o filme. Seja para ver o bombardeio de Halberstadt, cidade natal de Kluge, seja para ver a tragédia do incêndio do edifício Joelma, em São Paulo, em 1974. Em News and stories, no episódio Magazin: Feuer und Wasser, Kluge escala a proporção de 13 casas de bombeiros para 6 milhões de pessoas da cidade e conclui: não é uma proporção suficiente. Este mediador entre o olho e a imagem, às vezes com filtros coloridos e telescópios, posiciona entre imagens antigas a visão dos personagens e o espectador. ${ }^{2}$ Em A patriota, um joelho dá a medida da história alemã, deslocando o ponto de vista histórico e também o escópico, uma vez que o joelho se posiciona muito abaixo

2 Habermas, na ocasião do Prêmio Lessing, afirma: "I imagine Kluge standing at the telescope and observing the troop movements since November or September 1989, just as he did in 1968 and 1977. Straining his eyes, he observes a happier counterpart to Stalingrad - 45 years after the end of hostilities, something like the end of the War. Once again, it is the peripeteia which interests him, the climax and reversal" (HABERMAS, 2001. p. 119). 
do olho. O joelho morto diz: "como eu posso escapar de uma história que irá nos matar a todos?". Em $O$ assalto do presente contra o restante do tempo (1985), os pés do chofer Max são enquadrados telescopicamente, pois o tempo de seu patrão depende justamente deles. Esses exemplos são modelos de deslocamentos a partir dos quais Kluge oferece ao espectador uma montagem particular que redimensiona o espaço, o tempo e a história.

Uma questão a ser levantada sobre os argumentos da escalabilidade nos campos da computação e da economia é que eles podem se assemelhar à "estratégia de cima" que, por sua vez, é justamente a "organização de uma catástrofe", pois visa ao resultado final a ser alcançado por meio da perspectiva da eficiência. Strategy from above é o subtítulo do artigo de David Roberts que apresenta o seguinte argumento:

Pode ser que os bombardeiros que estão voando em direção a Halberstadt, vindos do sudoeste a 7000 metros, tenham uma "aparência tradicional de cavalaria", como se tivessem sido "condenados a cobrar". Essa aparência, no entanto, é o resultado puramente externo do cálculo da formação ideal de defesa - cálculos, que não podem ser vistos de baixo e que só podem ser "visíveis" nas apresentações esquemáticas dos manuais de táticas militares. A ordem dos grupos de batalha é mostrada em três perspectivas - lateral, traseira e frontal - e depois repetida quatro vezes em um diagrama de tamanho de página expandido, a fim de indicar esquematicamente em uma apropriada e "objetiva" forma a primeira, segunda, terceira etc. onda de bombardeiros, a sequência de bombas cai e também a produção em série dessas máquinas industriais voadoras (ROBERTS, 2012, p. 134-135).

Como contraposição à perspectiva "do acima", Roberts continua mostrando o escalonamento vertical up/down, pois no campo de baixo, o das pessoas da cidade bombardeada, a catástrofe permanece por 100 anos no passado e 100 anos no futuro. Ou seja, no learning process occurred. Será preciso uma estratégia que desfaça (undo) a história contínua, e o tempo-reverso significará uma mudança de perspectiva para tornar os eventos visíveis como uma relação histórica. Roberts lembra que Kluge e Oskar Negt, na obra Geschichte und eigensinn (História e obstinação, 1981), "querem esclarecer que acima e abaixo não se referem espacialmente a lugares, mas temporalmente ao lugar ocupado em uma relação histórica" (ROBERTS, 2012, p. 148). Logicamente a escalabidade up/down dos cartógrafos por si mesma não conseguiria evitar a guerra, apenas reposicionar a audiência espacialmente. Dessa forma, para fazer a reversão temporal, serão necessárias composições fílmicas que podem fazer compreender os 100 anos passados e os 100 anos futuros.

Retornando a Voltaire, observa-se que escalabilidade temporal é uma necessidade do gênero da ficção científica, pois obriga o narrador a realizar uma operação de projeção estendida de futuro longínquo dos objetos e narrativas. Ficções utópicas ou distópicas partem de elementos do presente, em alguns casos de histórias do passado, para produzir 
alguma projeção em espaço imaginado que serve como palco para experimentações em condições extremas. Uma forma de pensar na projeção do espaço exterior é que ele é um local especular que reflete os desejos e medos humanos, assim como Freud concebeu seu mecanismo para a manifestação dos sonhos. No início dos anos 1970, Kluge realizou dois filmes de ficção científica O grande caos (1971) e Willi Tobler (1972) sobre os quais pouco se fala. No caso dos dois filmes de Kluge, o espaço exterior é construído por pequenas peças de maquinário ordinário como tubos, cilindros, roldanas e parafusos, que filmados em planos muito próximos conseguem produzir imageticamente espaçonaves no espaço sideral com imagens que sugerem um céu estrelado infinito. ${ }^{3}$ No lugar da estética espacial hollywoodiana, como a do filme 2001, uma odisséia no espaço de Stanley Kubrick, um universo visivelmente precário. Apesar da estética do filme ter sido bastante comparada aos artifícios de Georges Méliès, Kluge conta com o imaginário cinemático de filmes de ficção científica para tornar sua ironia plausível e nisso se assemelha a Alphaville (1965) de Godard. Nessa obra, o Professor Von Braun é apresentado por meio de uma foto que se move e o computador Alpha 60, controlador de todo aquele universo, é uma luz que pisca. Ou seja, o cenário futurista é uma farsa que Godard concebe para se contrapor a Hollywood. ${ }^{4}$ No caso de $O$ grande caos de Alexander Kluge, o espectador é lançado ao espaço para encontrar os velhos problemas econômicos da terra em ambiente de revoltas, motins e o monokapitalism. Hollywood não é o foco, mas todo o sistema capitalista. Um problema a ser enfrentado no sistema estelar de Kruger é também a limitação humana, porque o espaço exterior não acomoda seres humanos: "Se o homem toma a si mesmo como uma medida, há apenas um objetivo muito quente ou muito frio no sistema solar", diz Kluge no filme.

Ao dimensionar um futuro próximo, no ano de 2034, Kluge avança para o passado com a teoria inicial do mono capitalismo de Marx, mas também com o presente que teme essa possibilidade como futuro. Kruger 60 poderia ser a Estrela vermelha de Alexander Bogdanov que, após a tentativa fracassada de revolução em 1905 na Rússia, escreveu sua ficção científica imaginando uma sociedade no futuro em escala comunista avançada, no planeta Marte. Bogdanov, juntamente com o periódico pulp sci-fi Perry Rhodan, é uma das poucas referências comentadas por Kluge como guia para estes filmes. ${ }^{5}$

É notável que o redimensionamento temporal tem a capacidade de reconduzir a narrativa pela repetição dos fatos do passado e do presente no tempo futuro, pois elenca um evento em diferentes tempos históricos e podem levar à conclusão comodista de que a repetição é inevitável, no domínio da farsa. Mas também, pelo contrário, poderá produzir a associação de que é tempo de mudança. Até pelo caráter cômico dos processos no filme. Pode parecer banal, mas não é comum o filme de ficção científica ter como foco central justamente o limbo narrativo. Muito pelo contrário, esse limbo narrativo, exaustivo em

3 Stollman diz que "as espaçonaves foram feitas das vísceras de televisões" (2007. p. 28).

4 Renner (2016, p. 43) e Fulk (2013) fazem essa associação.

5 Ver Renner (2016). 
Hollywood, acontece à mercê dos roteiristas, pois os personagens viajam em naves muito sofisticadas, encontram seres incomuns, às vezes biologicamente evoluídos e grotescos, mas sobretudo habitam sistemas feudais e militares através do quais se passam as tramas. Sobre esse tema, ainda que em contexto diferente, Kluge afirma, esperançoso:

Formar uma nova Humanidade é naturalmente possível, mas são necessários quinhentos anos, ou talvez mil anos. Mas o capitalismo também precisou de quatrocentos anos para estabelecer. A revolução agrária levou quatro mil anos. Nós temos que ser pacientes. A utopia se torna melhor e melhor quanto mais esperamos por ela (BJORKENHEIM, 2016).

\section{Montagem como compósito}

O aspecto material de construção fílmica impura de Kluge foi comparado aos filmes da época dos Nickelodeon pela historiadora Miriam Hansen (1988). A autora observa que "aglomerados de montagens que combinam imagens antigas, fotografias, slides de lanternas mágicas, ilustrações populares, títulos escritos, música em segunda mão e narração ocasional" (HANSEN, 1988, p. 178) suspendem o fluxo da narrativa de tradição identificatória. Hansen insiste que Kluge se recusa em transformar esse material em um blend homogêneo de disposição diegética. Esse aspecto em si é de grande importância na sua obra em relação ao tempo e a história. Lembrando que Kluge afirma em várias ocasiões que o cinema é o lugar da temporalidade, o uso de materiais diversos também revela uma temporalidade da realidade fílmica material, ou seja, os 48 quadros por segundo internos e 48 externos que acrescentam ao filme uma narrativa das máquinas de reprodutibilidade técnica. ${ }^{6}$

No caso de Kluge, o filme "impuro", composto por compilação de outros filmes, por mistura de imagens de desenhos e pinturas, antigos intertítulos, é ele mesmo um método. Se até um determinado momento da história do cinema era comum "filmar" o filme, a partir do procedimento de "cluster-montage", a composição fílmica se estabelece a partir de materiais que se juntam em um composto de várias mídias. O estranhamento Brechtiano, preocupação da geração de cineastas das "new waves" como Kluge, passa então a ser acompanhado por uma complexa arqueologia do dispositivo fílmico. Com a montagem disruptiva, o espectador não deixa de estabelecer uma relação com as camadas dessa composição quando foi deslocado temporalmente e espacialmente na observação do fenômeno. Nesse processo, enfrenta o embate das dimensões do compósito fílmico concebidas por Kluge como uma espécie de paralaxe que ousa funcionar mesmo na condição da realidade fílmica monocular do projetor refletido na tela. Ou seja, o filme e seus sentidos se tridimensionalizam, estereoscopicamente.

6 Kluge afirma: "If it is dark in the cinema for a 48th of a second and is exposed for 48 seconds, this is a flickering effect." In conversation with Edgar Reitz (2016, p. 98). 


\section{Nova escalabilidade dos computadores}

Desde o fim do século passado, os computadores e a internet produziram uma diversidade de objetos e gadgets que reconstituem a experiência do cinema com inúmeras novidades tecnológicas. Em muito, esse tempo se assemelha ao universo exploratório benjaminiano do início do século XX: planetários, keiserpanoramas, estereoscópios, panoramas. As máquinas óticas maravilharam Berlim e as metrópoles do início do século $\mathrm{XX}$, trazendo com elas a preocupação da teoria crítica de origem marxista que tentava compreender o encontro das "massas" com tais aparatos. A tarefa não era simples e, entre aqueles que se debruçaram sobre o encontro, Walter Benjamin talvez seja o que melhor tenha pensado no cinema como uma experiência sensorial e, por consequência, preocupado-se com a alienação dos sentidos. Miriam Hansen, por exemplo, para falar da alienação dos sentidos, resgata o conceito de "innervation" de Benjamin para se referir ao cinema como uma forma sensória ${ }^{7}$. Ela afirma que

a política da inervação que eu tento delinear em Benjamin envolve uma compreensão do cinema como uma forma sensória, psicossomática e estética que inclui, mas não se reduz às noções do pós-estruturalismo de escrita e leitura, por mais que psicanaliticamente flexionadas (HANSEN, 1999, p. 309).

Para Hansen, ao deslocar o conceito de "inconsciente ótico" de sua definição da imagem estática, na qual teria "abrigado uma reveladora função cognitiva", para a imagem em movimento, Benjamin consegue ampliar o potencial da função cognitiva "com uma função destrutiva, libertadora e transformadora, em relação ao mundo representado" (HANSEN, 2011, p. 160). Sobre o inconsciente ótico, Benjamin diz que "o ato de buscar um isqueiro ou uma colher é uma rotina familiar, mas dificilmente sabemos o que realmente acontece entre a mão e o metal" e também não sabemos "como isso flutua com nossos estados de ânimo". Benjamin lista os seguintes recursos obtidos pela câmera fílmica: "caindo e subindo, interrompendo e isolando, alongando e agitando o processo, aumentando e diminuindo o zoom" (BENJAMIN, 1999, p. 31). Se a fotografia "torna consciente pela primeira vez o inconsciente ótico", diz Benjamin referindo-se ao exemplo da "fração de um segundo" quando uma pessoa anda, o inconsciente ótico relacionado ao cinema está também relacionado à câmera que Godard chama de "instrumento", ao aparato como um todo e não ao conteúdo fílmico (BENJAMIN, 1999, p. 29). Avançando sobre o conceito de "inervação", o potencial cognitivo libertador e transformador do cinema inclui a tactilidade do filme, ultrapassando inclusive seu efeito óptico. O efeito háptico é o que garantirá a percepção espacial diante da "flatness" da tela de cinema. Da fotografia ao filme, como então pensar a função dos sentidos no deslocamento para a imagem digital, cuja materialidade de composição deixa de ser mimética?

7 O conceito de "inervação" de Benjamin foi primeiramente elaborado no seu ensaio "Surrealism: the Last Snapshot of the European Intelligentsia" de 1929 como "Inervação coletiva", cuja noção relaciona o corpo da humanidade e a tecnologia. Os veículos de produção da "inervação" são aqueles da reprodutibilidade técnica. 
Alexander Kluge sugere algumas indicações significativas para pensar o potencial cognitivo da imagem em movimento computadorizada. Em entrevista para Gary Indiana, ele diz que [...] "na realidade, metade da realidade não é consistente e você pode mudála, você pode observá-la e ela não mente". Indiana ironiza contra-argumentando que "Eu não sabia que você achava que era metade". E Kluge completa seu raciocínio tendo como apoio o procedimento computadorizado:

Bem, você não sabe exatamente, então você diz metade e metade como um bom comerciante diz. O filósofo Leibniz tinha uma teoria da chamada "separatrix", o "entre" duas coisas que são contradições. Há sempre uma linha. De um lado, isso é azul e isso é vermelho. Na realidade, o vermelho tem embaixadas no azul e o azul tem embaixadas no vermelho. E Leibniz diz que $50 \%$ dessa linha, essa estrutura "entre" é ordem e 50\% é anarquia. Esta é uma lei. É verdade, você pode perguntar a qualquer computador (INDIANA, 1989).

Além de legitimador da verdade, o computador surge na obra de Kluge no filme O ataque do presente contra o resto do tempo (1985) com a cena de uma família reunida em torno dele. Kluge sugere em um esquete a sua substituição da televisão, que, por sua vez, havia substituído a lareira. Edgar Reitz, em conversa com Kluge, confirma: "Eu acho que, por exemplo, a TV e também o computador nos apartamentos ocupam o lugar que o fogo da lareira tinha. A TV é o substituto do fogão" (REITZ, 2011, p. 98). No filme $O$ ataque, a voice-over de Kluge diz que "é um engano pensar que a nova mídia é entretenimento. É uma nova indústria". O pai usa o teclado, a filha observa atentamente a tela comendo uma maçã, a outra criança brinca com um alicate e a mãe amamenta o bebê - todos amontoados ao redor do computador. O pai consegue andar em quadrados de 15 metros, duas vezes ao dia.

Em outros sketches do filme, o patrão apressado deverá morrer em 1440 dias e sua morte se aproxima "minuto a minuto". Outro personagem, Dr. Von Gerlach, é um homem de decisões rápidas e não tem tempo para ver televisão. Kluge continua dizendo "tempo é o que se pode medir com um relógio. Uma criança, uma cidade, um amor, a morte são relógios". Os eventos do filme estão sendo reescalados a partir de tempos particulares de seus personagens. "Pode-se medir aquilo que consideramos passado, presente e futuro", mas todos querem fazer o presente durar bastante e Kluge conclui: "esta é a força da ilusão". Os relógios e a voz de Kluge dão lugar a uma demonstração da máquina cinematográfica dos irmãos Lumière: o cinema é o ataque do presente? Após este sketch inicia-se a história do diretor cego, um iconoclasta que odeia imagens. Ao final, a voz afirma que "por dentro, ele estava cheio de imagens". Novamente o cinematógrafo e o trem chegando à estação.

Em dado momento, Kluge reajusta a linha divisória que Benjamin coloca no ensaio "A obra de arte", entre as artes clássicas e o cinema, argumentando que tal linha não estaria sequer entre o cinema e a televisão, mas entre o cinema e "a mídia eletrônica 
de propriedade privada" (HANSEN, 1988, p. 184). Tendo em vista a avassaladora entrada de computadores nas casas e no trabalho, substituindo a televisão, o cinema, o quadro de parede, o porta-retratos, a máquina de escrever, o livro, o rádio, a vitrola, o instrumento musical, resumindo, a lareira, como escalonar tais universos? Os dispositivos computadorizados se multiplicam. O ambiente do início do século XXI se assemelha ao do século XX em possibilidades. Pode-se filmar, editar, distribuir e assistir a filmes em escala inimaginável para uma pessoa que teria sonhado em ampliar a liberdade dos processos fílmicos anos atrás.

Para finalizar, transcrevo três momentos de uma longa entrevista que fiz com Alexander Kluge sobre esse assunto ${ }^{8}$ :

Eu acho que a situação é semelhante à virada do século anterior, no início da história do cinema. Eu não diria que é mais democrática, mas com certeza hoje as pessoas têm a possibilidade de participação muito maior. A pressão da sociedade sobre as pessoas é maior do que na virada do século anterior, mas as pessoas conseguem encontrar mais caminhos alternativos. As pessoas conseguem encontrar seus desvios mais facilmente. Que poeta poderia ter imaginado a Internet? Existe um centro de ciências na Suíça o "CERNE" que pesquisa o início do universo e pesquisa também as partículas menores que existem no universo. Estes pesquisadores que fundaram a Internet e o Pentágono tentaram se apoderar da tecnologia, mas as pessoas se apoderaram da Internet com ferramentas como o "YOUTUBE" e conseguiram criar uma esfera pública mais revolucionária do que a própria criação do livro impresso. E hoje se luta nessa esfera, entretanto é um espaço que não pode ser ocupado nem pela censura e nem pelas grandes corporações (DE ALMEIDA, 2011).

A obra de Kluge não deixa de ser a obra da montagem associativa, dos confrontos entre os fatos e os fakes, dos contrastes e dissociações. Mas essas anotações consideram Kluge um cientista-artista que concatena cadeias as mais inesperadas, às vezes de cruel obviedade como King-Kong e o avião das torres gêmeas, conduzindo-nos a um processo contínuo de reescalonamento das medidas de tempo e espaço. Para produzir esse efeito, tais cadeias não se associam nem se dissociam em linha reta e fina, mas constroem compósitos de cadeias. Talvez seja justamente o efeito háptico da substancialidade das camadas que compõem as tais cadeias aquele que poderá evitar a catástrofe, pelo seu efeito sensorial. E quem sabe auxiliar a dirigir um filme às cegas.

E acho muito interessante que você, Jane, tenha comparado o advento da Internet ao início da história do cinema. Naquele momento, no início do cinema, foi uma espécie de primeira "globalização" como é descrito por Walter Benjamin em sua obra "Passagens". Lembremos também da velocidade com que o mundo naquele

8 Entrevista inédita conduzida por mim no dia 29 de novembro de 2011, por skype, em 3 diferentes locais, Kluge em Munique, eu em São Paulo e uma audiência de pesquisadores marxistas e admiradores da obra de Kluge, no Museu da Imagem e do Som em Campinas. Participaram da entrevista Paulo Oliveira e Francisco Martorano. A transmissão de imagem skype não funcionou apropriadamente, mas tivemos uma ótima conversa sonora. 
momento andou em direção à catástrofe de 1914. E nesse momento do século XX o mundo saiu dos trilhos. Nós tivemos praticamente 30 anos de guerra até 1945. O pior de tudo não é só a guerra, mas principalmente o massacre em Auschwitz. Não se pode mais confiar na civilização. E a questão é: será que o século XXI conseguirá não sair dos trilhos? Será que isto pode ser evitado? Isto é um tema para teoria e, também, é um tema também para o cinema (DE ALMEIDA, 2011).

Agora, depois de alguns anos, a resposta se associa ao elefante bêbado. Há, entre as duas respostas, um gap com várias instigantes questões políticas, tecnológicas, psicanalíticas, astronômicas de uma conversa intelectual marcante. E Godard. Eis o último comentário da entrevista, na esperança de que ele reforce meus argumentos:

[...] Eu não queria passar a imagem de que eu não gosto dos computadores. Eu gosto deles, sobretudo à noite quando eles acendem as luzes. Pode sim ser pensado como uma espécie de viajante que veio de Sirius. Interessante nos aproximar dele. O computador serve para aproximar as pessoas, mas ao mesmo tempo ele é muito distante do ser humano na sua conformação. Os computadores são uma espécie de mundo paralelo em relação ao nosso, mas eu posso até pensar em um computador como um "bichinho de estimação". "Alice no país das maravilhas" seria talvez uma bela metáfora para descrever os computadores, mas se eu lhe devolver esta pergunta como você responderia à pergunta que fez? Seriam os computadores seres de Sirius viajando para Terra?

Jane de Almeida é professora do Programa de PósGraduação em Educação, Arte e História da Cultura da Universidade Mackenzie e professora visitante do Departamento de Artes Visuais da Universidade da Califórnia, San Diego. Organizadora do livro Alexander Kluge: o quinto ato (CosacNaify), entre outros.

janedealmeida@post.harvard.edu

\section{Referências}

ARBERRY, A. J. The elephant in the dark, on the reconciliation of contrarieties. In: Tales from Masnavi of Rumi, Mai 2004. 29 - 08 - 2006, p. 71.

BENJAMIN, W. Little History of Photography. In: Walter Benjamin Selected Writings 1927-1934. vol. 02, Cambridge (etc.): The Belknap Press of Harvard University, 1999

BJORKENHEIM, C. Alexander Kluge Interview. In: Screen Slate, 10-24-2016. [https://www.screenslate. com/articles/11].

DAVIDSON, J. E. A kind of species memory: the time of the elephants in the space of Alexander Kluge's cinematic principle. In: New Directions in German Cinema, Eds. Paul Cooke, Chris Homewood. London (etc.): I.B Tauris, 2011. 
DE ALMEIDA, J. On Elephants, Telescopes, Microscopes, Cartography, Aliens, and Computers: Notes on Scalability in Alexander Kluge's Works. In: Stichwort: Kooperation. Alexander Kluge-Jahrbuch. Volume 3. Ed. Rainer Stollmann, Thomas Combrink, Gunther Martens. Vandenhoeck \& Ruprecht Unipress, Göttingen: 2017. pp. 261-276.

. Escalabilidade. In: Revista Trama Interdisciplinar. São Paulo, v. 5, n. 3, p. 32-37, dez. 2014. [http://editorarevistas.mackenzie.br/index.php/tint/article/view/7751/5170]

. Entrevista inédita com Alexander Kluge. 2011.

EVANS, J. The History and Practice of Ancient Astronomy. New York: Oxford University Press, 1998.

HABERMAS, J. The Useful Mole who Ruins the Beautiful Lawn. The Lessing Prize for Alexander Kluge. In: The Liberating Power of Symbols. Philosophical Essays. translated by Peter Dews, Cambridge: The MIT Press, 2001.

HANSEN, M. Reinventing the Nickelodeon: Notes on Kluge and Early Cinema. In: Alexander Kluge: Theoretical Writings, Stories, and an Interview, vol. 46, 1988, p. 178 - 198.

. Benjamin and Cinema: Not a One-Way Street. In: Critical Inquiry, 1999.

Cinema and Experience: Siegfried Kracauer, Walter Benjamin, and Theodor W. Adorno. Berkeley (etc.): University of California Press, 2011.

INDIANA, G. Alexander Kluge by Gary Indiana. In: Bomb Magazine. vol. 27, 1989. [http:// bombmagazine.org/article/1192/alexander-kluge].

OBRIST, H. U. What Art Can Do. in: E-Flux. Journal, vol. 81, April 2017. [http://www.e-flux.com/ journal/81/126634/what-art-can-do/].

PAVSEK, C. Features. The Stubborn Utopian: The Films of Alexander Kluge. In: Cinema Scope. [www: http://cinema-scope.com/cinema-scope-magazine/features-the-stubborn-utopian-the-filmsof-alexander-kluge/].

RADKAU, J. The Heroic Ecstasy of Drunken Elephants: The Substrate of Nature in Max Weber - a Missing Link between his Life and Work. In: Biography between Structure and Agency: Central European Lives in International Historiography, eds. Von Volker Berghahn and Simone Lässig. New York: Berghahn Books, 2008.

RENNER, R. G. Zurück in die Gegenwart - Zu Kluges Science-Fiction-Projekt Der große Verhau. In: Alexander Kluge-Jahrbuch. vol. 03, Eds.: Richard Langston, Gunther Martens, Vincent Pauval, Christian Schulte und Rainer Stollmann, Göttingen: V\&R Unipress, 2016.

ROBERTS, D. Alexander Kluge and German History: 'The Air Raid on Halberstadt on 8.4.1945'. In: Alexander Kluge. Raw Materials for the Imagination. Ed. Tara Forrest. Amsterdam: Amsterdam University Press, 2012.

STOLLMAN, R. Fatos e fakes. In: Alexander Kluge: o quinto ato. Ed. Jane de Almeida. São Paulo: Cosac \& Naify: 2007. 